\title{
Metal Imaging on Surface of Micro- and Nanoelectronic Devices by Laser Ablation Inductively Coupled Plasma Mass Spectrometry and Possibility to Measure at Nanometer Range
}

\author{
Myroslav V. Zoriy, ${ }^{\text {a }}$ Dirk Mayer, ${ }^{\mathrm{b}}$ and J. Sabine Becker ${ }^{\mathrm{a}}$ \\ ${ }^{a}$ Central Division of Analytical Chemistry, Research Centre Juelich, Juelich, Germany \\ ${ }^{\mathrm{b}}$ Institute of Bio- and Nanosystems, Research Centre Juelich, Juelich, Germany
}

An analytical mass spectrometric method for the elemental analysis of nano-bioelectronic devices involved in bioengineering research was developed and applied for measurements of selected metals ( $\mathrm{Au}, \mathrm{Ti}, \mathrm{Pt}, \mathrm{Cr}$, etc.) on interdigitated electrode array chips (IDA-chip). An imaging laser ablation inductively coupled plasma mass spectrometric (LA-ICP-MS) procedure was used to map the elements of interest on the surface of the analyzed sample. The obtained images of metals were in a good agreement and corresponded to the micro- and nanofabricated metal electrode pattern. For the analysis at nanometer resolution scale a NF-LA-ICP-MS (NF-near-field) procedure was applied, which utilize thin Ag needle to enhance laser beam energy and improve spatial resolution of the method. The results show a $\sim 100 \times$ enhancement of analyte signal, when the needle was positioned in the "near-field region" to the sample surface and the laser shot was performed. In addition, mass spectrometric studies of reproducibly for five separated NF-LA shots in different places of analyzed sample yielded an RSD of the measurement of 16\%. (J Am Soc Mass Spectrom 2009, 20, 883-890) (c) 2009 American Society for Mass Spectrometry

B io engineering (or biological engineering), including biomedical engineering and nanobiotechnology, is a new, challenging, and rapidly growing high-tech research field [1, 2]. The use of biomolecules as the building blocks of higher-level functional devices will lead to applications that range from the integration of biomaterials with electronics in recognition or sensing devices [3]. Bioelectronics research also exploits to use biomolecules to perform the electronic functions that semiconductor devices currently perform, thereby offering the potential to increase integration in combination with additional functionality at the nanometer level. However, the integration of biomolecules or even whole cells with inorganic devices brings several challenges about as there are, for instance, operation of the electronic components under physiological conditions, electrically, biochemically as well as size-adapted bioinorganic interfaces, and biocompatibility of the electronic devices. The implementation of these challenges and the realization of functional bioelectronic junctions require interdisciplinary research, including microengineering, biotechnology, surface chemistry, and analytical research.

Address reprint requests to Dr. M. V. Zoriy, Central Division of Analytical Chemistry, Research Centre Juelich, D-52425 Juelich, Germany. E-mail: m.zoriy@fz-juelich.de
The fabrication of bioelectronic component on the basis of silicon microtechnology facilitates high integration densities, high spatial resolution, combining signal recording and transducing in one device at relatively low production costs. To build and assemble bioinorganic electronic components with well defined and optimized features, it usually requires control over impurities of trace levels contaminations, which can influence the physical, electrical, magnetic, and chemical properties of thin layered systems. In particular, the biocompatibility of device can be strongly affected by organic and inorganic impurities introduced during the fabrication processes. Therefore, powerful and sensitive trace analytical techniques are necessary for the characterization of deposited noble metal layers and nanoclusters in bioengineering devices at $\mu \mathrm{m}$ and $\mathrm{nm}$ lateral resolution scale.

Currently there exist a number of analytical techniques capable for bulk and microlocal quantitative analyses. Surface analytical techniques, such as scanning electron microscopy with energy dispersive X-ray analysis (SEM-EDX) [4, 5], proton-induced X-ray emission (PIXE) [6, 7] are generally not sensitive enough for trace analysis. Using secondary ion mass spectrometry (SIMS) $[8,9]$, it is possible to produce metal images of solid sample surface with a spatial resolution in the low $\mu \mathrm{m}$ and sub- $\mu \mathrm{m}$ range [10]. 
Laser ablation inductively coupled plasma mass spectrometry (LA-ICP-MS) is becoming the method of choice for the trace element, ultratrace and isotope analysis of solid samples and is already the most important laser-induced technique in inorganic mass spectrometry due to the advantage of direct solid sampling by focused laser radiation on the sample surface, the easy quantification possibility and its ability to provide microscale information [1, 11, 12].

The main field of application for LA-ICP-MS is in geological research, including geochronology, isotope variation in nature, and geochemistry [13-17]. LAICP-MS is established as a powerful and sensitive analytical technique in material and environmental research, in particular, for the investigation of highpurity materials, superhard materials of layered systems, or for monitoring of long-lived radionuclides in contaminated soil samples $[18,19]$. As a new application field LA-ICP-MS is employed in biological and medical research $[20,21]$ for image (mapping) of the lateral element distribution in an entire sample $[13,14$, 22-26]. As an example, imaging LA-ICP-MS techniques were developed [27] for quantitative mapping of selected elements $(\mathrm{P}, \mathrm{S}, \mathrm{Fe}, \mathrm{Cu}, \mathrm{Zn}$, and $\mathrm{C})$ in thin sections of brain samples, infected and noninfected with tumor (thickness $20 \mu \mathrm{m}$ ). The LA-ICP-MS images obtained for $\mathrm{P}, \mathrm{S}, \mathrm{Fe} \mathrm{Cu}$, and $\mathrm{Zn}$ were quantified using synthetically prepared matrix-matched laboratory standards.

However, in spite of all the advantages of the LAICP-MS technique, its application in some analytical tasks is limited by the restriction in focusing the laser beam due to the diffraction feature of the light and, therefore, a finite lateral resolution (from 5 to $300 \mu \mathrm{m}$ $[1,28,29]$ that, in some cases, would be insufficient, for example, for the analysis of the fine structures of small regions of biological tissues and single cells $[14,19,20]$ or in nanoelectronics [21]. For this reason, the known near-field effect can be applied to improve the spatial resolution of the laser that, recently, has proven the capability of the LA-ICP-MS technique for possible spatial analysis at $\mathrm{nm}$ resolution scale. The principle of the procedure is to apply an enhancement of incident laser energy (light) on the tip of a thin Ag needle (diameter $\sim 200 \mathrm{~nm}$ ). "Focused" in this way, the laser beam will produce an ablation crater in the size proportional to the needle diameter used [30, 31]. An experimental arrangement of NF-LA-ICP-MS (including controlling system for sample-to-tip distance via the measurements of tunnel current between the needle and sample surface) was successfully established in our laboratory and applied for nanolocal analysis of thin (20 $\mathrm{nm}) \mathrm{Au}$ film deposited onto a Si substrate [30]. The observed craters ranged from $500 \mathrm{~nm}$ to about $1 \mu \mathrm{m}$ in diameter and were dependent on the needle used as well as on the "sample-to-tip" distance.

The aim of the present study was to develop analytical procedure for imaging element of interest on the surface of interdigitated electronic array chip (IDA- chip) a microfabricated bio-inorganic electronic component, that comprises two-dimensional macro-, micro-, as well as nano-electrodes, and are intensively used for the study of fundamental investigations in bioelectronics. First, the analyzed sample was screened with LAICP-MS method to map the distribution of selected metals on the sample surface. After that an experimental setup of established NF-LA-ICP-MS procedure was applied to evaluate the possibility of analysis of IDAchip bioelectronic device at nanometer resolution scale. The results of the imaging LA-ICP-MS as well as followed NF-LA-ICP-MS measurements are presented.

\section{Experimental}

\section{Instrumentation}

Imaging LA-ICP-MS measurements of IDA-chip bioelectronic device. For all imaging studies by LA-ICP-MS, a commercial laser ablation system using a Nd:YAG laser (NewWave UP 266; Fremont, CA) is coupled to a quadrupole-based inductively coupled plasma mass spectrometer (ICP-QMS, Agilent 7500, Agilent Technologies, Santa Clara, CA). The diameter of the laser crater was about $200 \mu \mathrm{m}$. The measurement time for imaging LA-ICP-MS was about $4 \mathrm{~h}$, scan speed applied - $60 \mu \mathrm{m}$ $\mathrm{s}^{-1}$ with the repetition rate of $20 \mathrm{~Hz}$. Further details about the instrumentation used can be found elsewhere $[12,26]$.

NF-LA-ICP-MS measurements of IDA-chip bioelectronic device at nanometer scale. A Nd:YAG Continuum Surelite; (Santa Clara, CA) laser was used to produce a laser beam of $532 \mathrm{~nm}(\mathrm{~d} \sim 7 \mathrm{~mm})$. No focusing lenses were applied; the unfocused laser beam was enhanced on the analyzed surface by means of a thin silver needle (tip diameter of about $200 \mathrm{~nm}$ ). To detect the quantity of ablated material during near-field laser ablation a double-focusing sector field inductively coupled plasma mass spectrometer (ICP-SFMS) Element 1, Thermo Fisher Scientific (Bremen, Germany) was applied ensuring the highest sensitivity achievable. The laser-ablated material (with and without near-field enhancement) was transported with argon to the inductively coupled plasma mass spectrometer and analyzed. For the measurements at nanometer spatial resolution a LAchamber with relatively small internal volume (about 40 $\mathrm{cm}^{3}$ ) with an embedded piezo manipulator (z-direction) as well as "sample-to-tip" distance controlling system were developed. The "burst" shots laser ablation running mode was selected. In the Figure 1, schematic arrangements of developed experimental setup for near-field laser ablation procedure is presented. To minimize the vibrations during the measurements the Iso-Plate vibration damping system from Thorlabs Inc. (Newton, NJ) was used. Further details about NF-LA-ICP-MS experimental setup can be found elsewhere [30, 31]. 


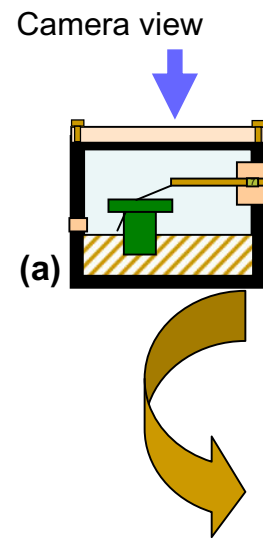

(b)

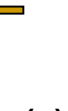

(c)

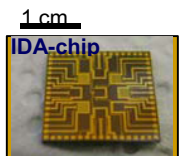

(d)
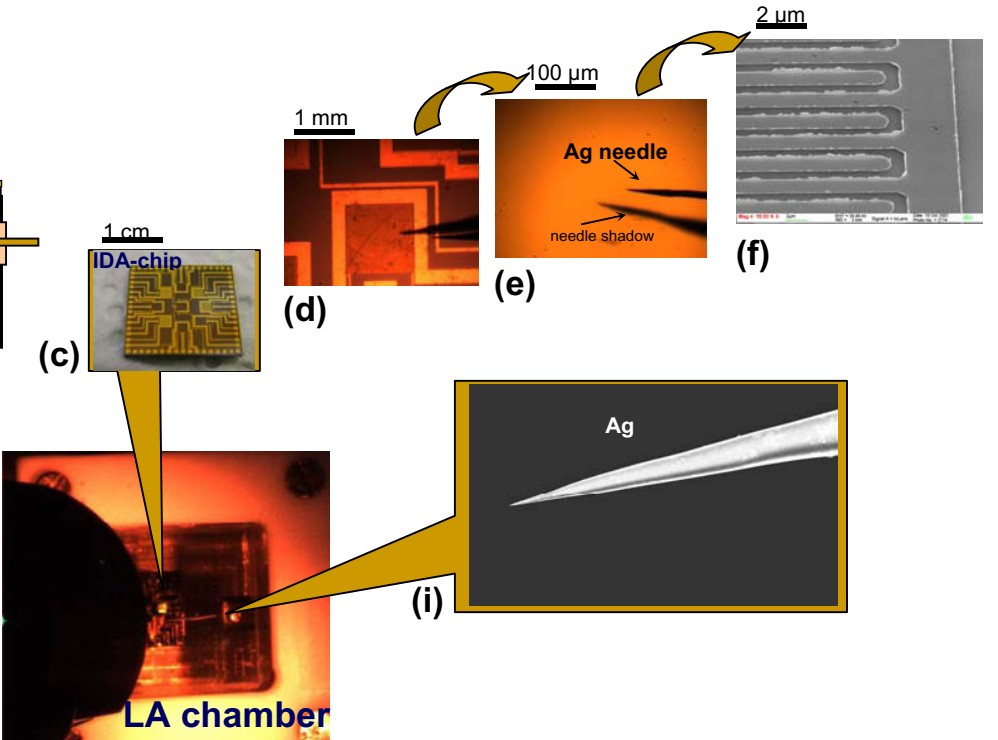

Figure 1. Schematic setup of developed NF-LA-ICP-MS ablation procedure. (a) and (b): Schema and camera view of ablation chamber, respectively; (c)-(f): Sample view in different resolution scalar; i) - SEM image of used Ag needle.

\section{Samples and Sample Preparation}

Each electrode unit comprises two opposing arrays of interconnected and interdigitated micro- and nanosized metal electrodes. The interdigitated working electrodes facilitate a very sensitive detection of electroactive species by means of redox cycling processes. A multiple oxidation and reduction of redox active molecules at oppositely biased working electrodes (positive and negative of the redox potential of the molecule) is used within concept of redox cycling to enhance the current response. The close proximity of the supporting electrodes reduces the response time of the electrochemical cell as well as ohmic drop effects. In sum, one IDA chip contains nine pairs of interdigitated electrodes, which differ in width and spacing of the individual electrodes branches ranging from $2 \mu \mathrm{m}$ to 700 $\mathrm{nm}$ and $2 \mu \mathrm{m}$ to $1 \mu \mathrm{m}$, respectively, Figure 2 . The variation in electrode spacing facilitates kinetic investigations, since transport phenomena and critical path length can be estimated with this setup. Furthermore, the redox current increases with decreasing gaps between the electrodes as long as the diffusion is the r-limiting step of the redox cycling process. Each IDA electrode array contains an on chip reference and counter electrode in addition to the working electrodes.

The metal IDA chips were fabricated on $1.5 \mathrm{~cm}$ $n$-type 110 silicon wafers. One wafer contains 36 chips each with a square area of $11 \times 11 \mathrm{~mm}^{2}$. The wafers were covered by a SiO2 layer of a thickness of $1000 \mathrm{~nm}$. A photoresist AZ nLOF 2020 was used for the optical lithography. A $10 \mathrm{~nm}$ layer of titanium was deposited on the wafer, followed by a $10 \mathrm{~nm}$ layer of platinum, and finally $150 \mathrm{~nm}$ layer of gold. The removal of the excess metal and the defining of the electrode structures were done by a lift-off process in N-methylpyrrolidone (NMP).

\section{Measurements Procedure}

To control the quality of preparation procedure, the produced IDA chip was screened for its lateral elements distribution using imaging LA-ICP-MS technique. In addition, to improve the resolution property, NF-LAICP-MS method was applied. Details about the measurements procedures used are given below.

For imaging of metals by LA-ICP-MS at $\mu \mathrm{m}$ resolution. The experimental parameters of LA-ICP-MS were optimized with respect to the maximum ion intensity of ${ }^{197} \mathrm{Au}^{+}$using the laboratory standard solution with a

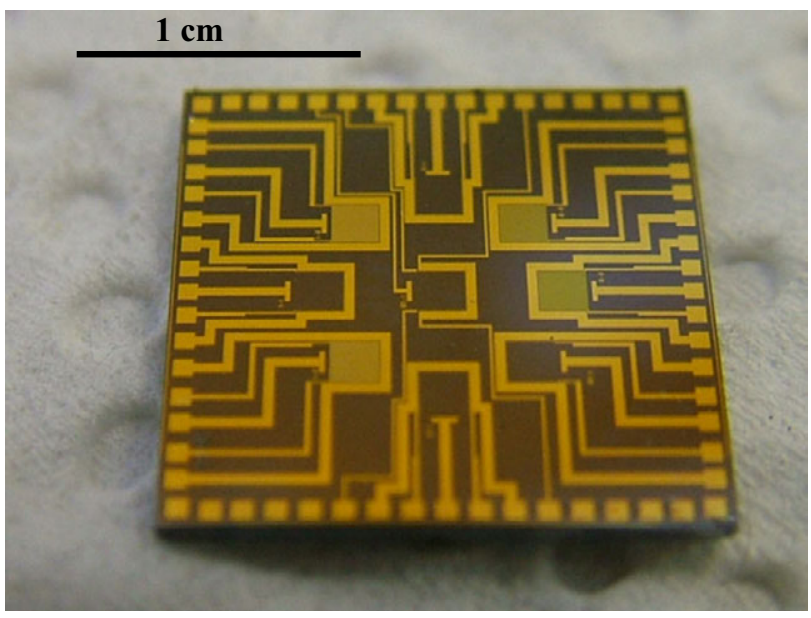

Figure 2. Photograph of analyzed IDA-chip bioelectronic device. 
concentration of gold of $5 \mu \mathrm{g} \mathrm{mL} \mathrm{L}^{-1}$. Maximum ion intensity was observed at a carrier gas flow rate of $1.1 \mathrm{~L}$ $\mathrm{min}^{-1}$ for the transport of ablated material to the ICPMS. The analyzed IDA-chip was investigated by LAICP-MS with respect to the distribution of $\mathrm{Au}, \mathrm{Pt}$, $\mathrm{Ti}$, and $\mathrm{Cr}$ as the selected metals. To obtain twodimensional images of element distribution, the region of interest was systematically screened by a focused laser beam (line by line). In total, 100 lines were scanned through the analyzed chip surface, so that all produced layers (e.g., Au, Ti, Pt) were completely removed. ICP-MS data files for each analyzed IDA chip were converted into txt file and were used to produce 2D images of element distribution. The images were plotted using programming script in MATLAB 6.5 computing software (The MathWorks, Inc., Natick, MA). Further details about the measurements procedure used are described elsewhere [32-34].

For nanolocal analysis by NF-LA-ICP-MS at nm resolution. To study the figures of merit of the NF-LAICP-MS procedure on bioelectronic device different experimental conditions were employed. Ion intensity of ${ }^{197} \mathrm{Au}^{+}$was measured during "single shots" of the unfocused laser when the tip of the thin Ag needle far (d >10 mm), no near-field enhancement was observed; and at a distance of the needle about $10 \mathrm{~nm}$ (and lower) from the sample surface, near-field enhancement of incident laser energy took place. The controlling of tip-to-sample distance was performed via measurement of tunnel current by developed tuning system as described elsewhere [30, 31]. First, the needle slowly approached the sample surface (no tunnel current was measured). When the needle was about $1 \mathrm{~nm}$ from the sample surface (corresponding to a tunnel current of about $1 \mathrm{nA}$ [31], specially developed software triggered the piezo to keep this position constant. It was then possible to move the piezo (with the sample) to a defined distance from the needle tip. In addition, the experiments were performed with a continuously running laser at a repetition frequency of $10 \mathrm{~Hz}$. Under these experimental conditions, the needle approached the sample surface very slowly and the mass spectrometric signal of ablated $\mathrm{Au}$ was monitored with the running laser. Further details of the measurement procedure used can be found elsewhere [30, 31].

\section{Results and Discussion}

\section{Imaging LA-ICP-MS of Metals on IDA Chip Bioelectronic Device}

The microfabricated IDA was mapped by developed imaging LA-ICP-MS method with $\mu \mathrm{m}$ resolution for the distribution of $\mathrm{Au}, \mathrm{Ti}, \mathrm{Pt}$, the elements that are relevant for both the physical properties as well as for biocompatibility of the bioelectronic device (see schematic structure of IDA device in Figure $2 b$ ) as well as $\mathrm{Cr}$, which was considered to be an impurity element during sample fabrication procedure. In Figure 3a, the lateral distribution of $\mathrm{Au}$ over a whole surface of analyzed bioelectronic device is shown. The obtained image clearly correlated with the designed layout of the electrode pattern. All the connection leads (electrodes) of the conductive $\mathrm{Au}$ were uniformly situated, however in the middle squares (electrode arrays are localized) an inhomogeneous gold distribution (variable color in Figure 3a) was observed due to the different integration density of the interdigitated electrodes. Electrodes with $2 \mu \mathrm{m}$ width of the electrode branches and $1 \mu \mathrm{m}$ spacing showed highest intensity of gold. The overall maximum ion intensity of ${ }^{197} \mathrm{Au}^{+}$observed was in the range of $5 \times$ $10^{7} \mathrm{cps}$ on the conductive bands while in between those bands (blank value) an intensity of about 500 cps was measured.

In Figure $3 \mathrm{~b}$ and $\mathrm{c}$, the distributions of $\mathrm{Ti}$ and $\mathrm{Pt}$, from the layers (each of $10 \mathrm{~nm}$ of thin) that were located under the Au layer are shown. As it was expected, the images show a similar distribution pattern with the maximum ion intensities $4 \times 10^{6}$ and $3 \times 10^{6} \mathrm{cps}$, respectively, which corresponds to the relations of the thicknesses between measured $\mathrm{Au}, \mathrm{Ti}$, and Pt layers (in fabrication procedure, IDA-chip produced Au layer was much thicker than that of the $\mathrm{Ti}$ and $\mathrm{Pt}$, see Figure 2b). In addition, by developed imaging LA-ICP-MS procedure the distribution of $\mathrm{Cr}$ through the analyzed surface of IDA-chip was determined (see Figure 3d). Cr was considered to be an impurity and could seriously affect the biocompatibility of bioelectronic devices. The results show clear chromium enrichment in the electrodes bands (ion intensity of about $20 \mathrm{cps}$ ) while in between bands the intensity in the range below $50 \mathrm{cps}$ was observed. The quantification of $\mathrm{Cr}$ content in analyzed sample was performed using the analysis equation $[35,36]$ and taking into consideration that the relative sensitivity coefficient $(\mathrm{RSC})=1$. The calculation shows that $\mathrm{Cr}$ concentration in analyzed IDA-chip (electrodes bands) was in the range of $10-20 \mu \mathrm{g} \mathrm{g}^{-1}$. This found concentration of $\mathrm{Cr}$ is considered to be uncritical for performing cell and protein based bioelectronic measurements. No indication of heavy metal effect was observed during the use of chip of the same wafer.

Using such an imaging method, it was possible after the producing of IDA-chip to evaluate the preparation procedure as well as to better understand its physical basics and find the optimal experimental conditions.

\section{Near-Field Laser Ablation Studies on IDA-Chip Bioelectronic Device}

To evaluate the possibility to study produced IDA-chip in $\mathrm{nm}$ resolution scale, an analytical procedure of NFLA-ICP-MS was developed. The method utilized a measurement algorithm as described earlier [30], where mass spectrometric signals of $\mathrm{Au}$ were monitored during laser illumination of the thin silver needle that was 

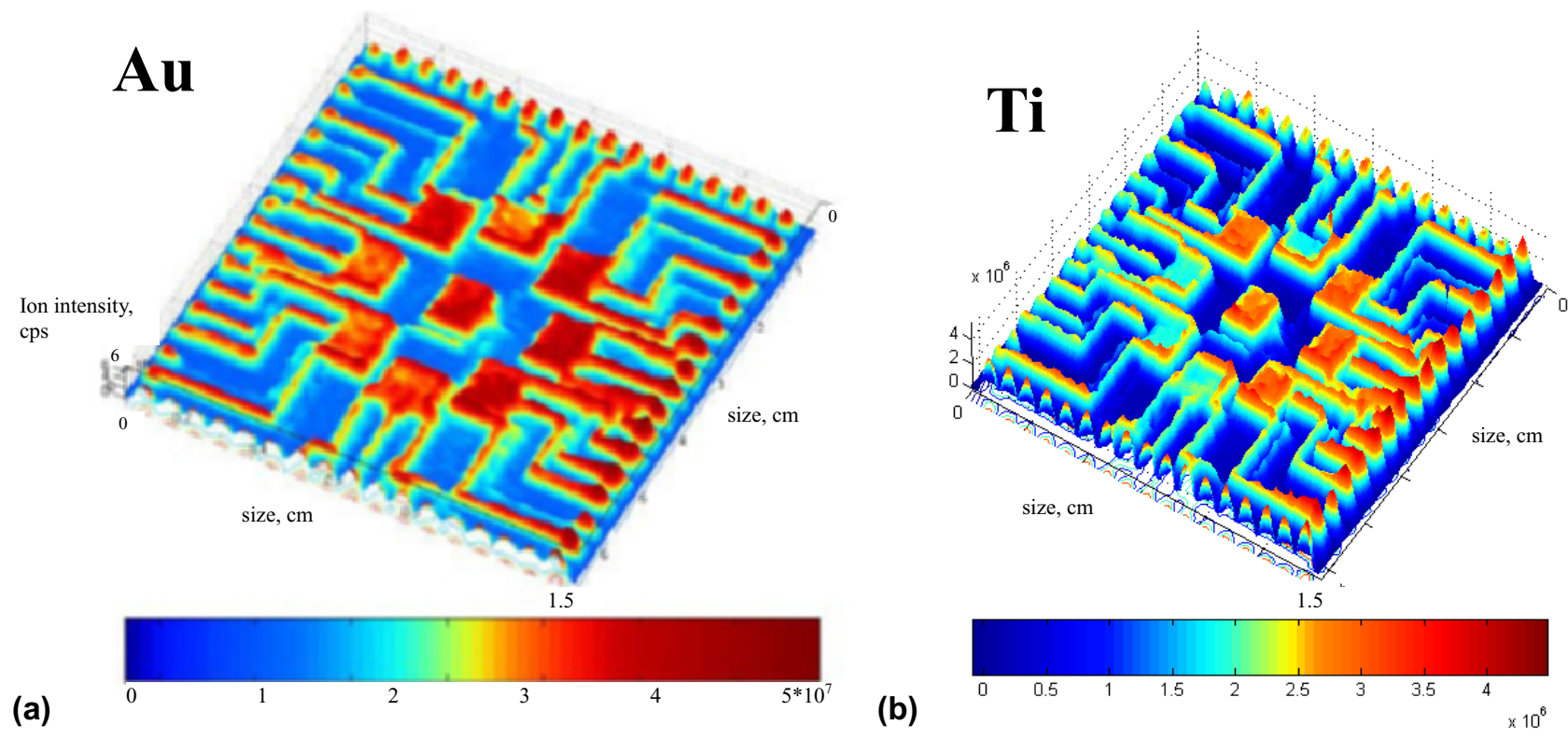

(b)
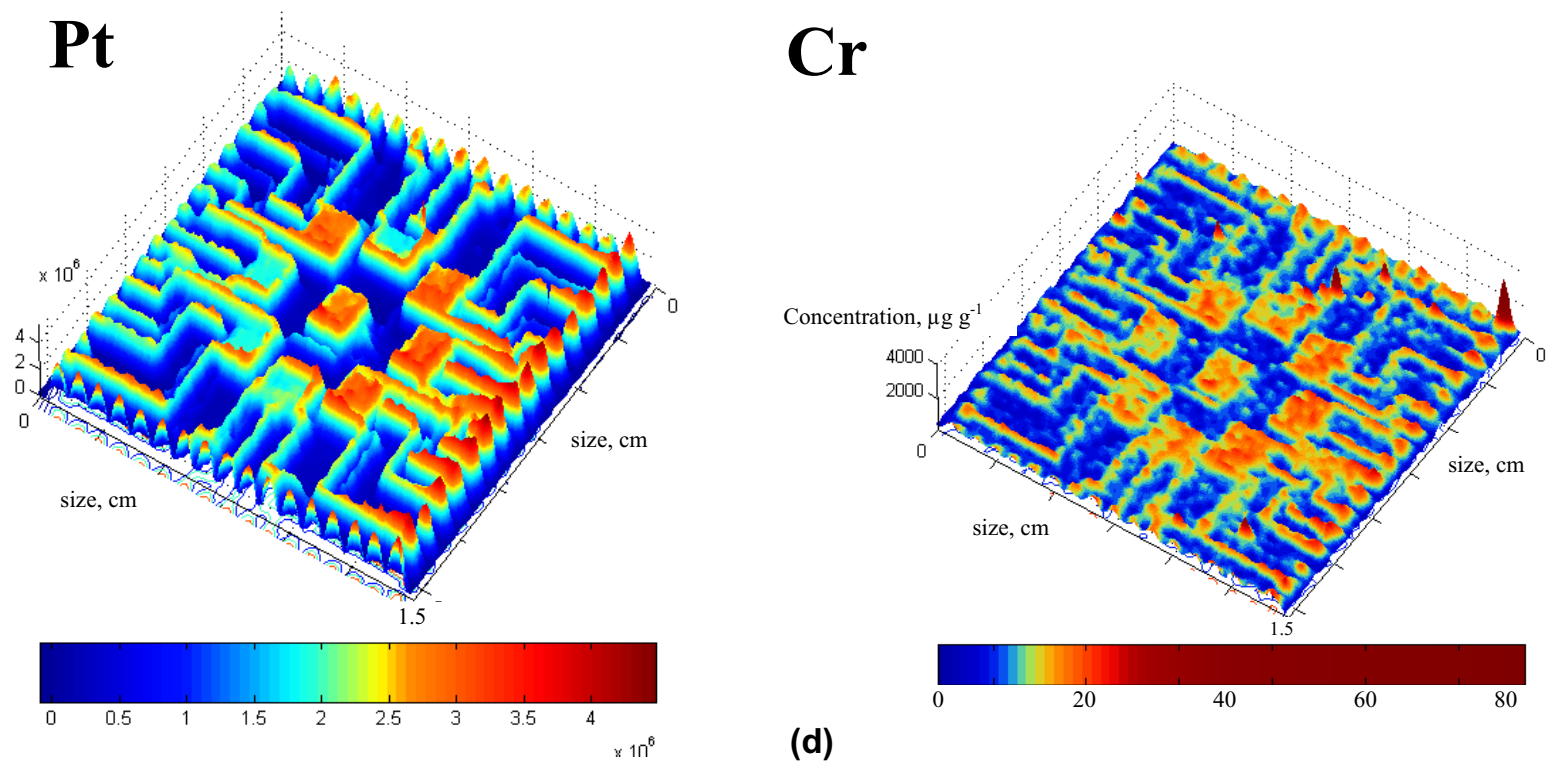

(c)

Figure 3. Distribution profile of $(\mathbf{a})$ : $\mathrm{Au},(\mathbf{b}): \mathrm{Ti},(\mathbf{c}): \mathrm{Pt}$, and $(\mathbf{d})$ : $\mathrm{Cr}$ on analyzed IDA-chip measured by developed imaging LA-ICP-MS procedure.

positioned near in closeness to the sample surface (1-10 $\mathrm{nm}$, "near-field region") and in a relatively large distance (about $10 \mathrm{~mm}$, "far field" region). In Figure 4, transient signals of ${ }^{197} \mathrm{Au}^{+}$as well as ${ }^{107} \mathrm{Ag}^{+}$(to access information about the ablation of needle material during the NF-LA enhancement) of such measurements on the selected regions (different places in region $\mathrm{A}$ of Figure $4 \mathrm{~d}$ ) on analyzed IDA bioelectric device are shown. First, the needle was placed in about $10 \mathrm{~mm}$ from the sample surface and three single laser shots (defocused laser beam) on different places on analyzed sample (see inset d) were performed (at the time of 60, 105, and $160 \mathrm{~s}$, respectively). As shown in the insets $a, b$, and $\mathrm{c}$, no ablation of $\mathrm{Au}$ and Ag occurred (only a background signal was observed). After that using the developed experimental setup, the needle was posi- tioned in the distance of about $1 \mathrm{~nm}$ from the sample surface and under same ablation condition conditions (e.g., laser fluence, beam size, etc.) additional three shots (fourth, fifth, and sixth, each in another place) were done. In this case, the laser energy was enhanced via the near-field that was sufficient for ablation of Au. Depending on the place analyzed the ion intensities of ${ }^{197} \mathrm{Au}^{+}$in the range $1600-3000 \mathrm{cps}(\mathrm{RSD}=16 \%$ ) were determined. Such a difference in observed intensities could be most probably explained by the roughness of the sample surface (in nm range) as well as its local inhomogeneity or contaminations. In contrast to the ${ }^{197} \mathrm{Au}^{+}$, no ablation of ${ }^{107} \mathrm{Ag}^{+}$was observed during the experiments when the needle was far away from the sample surface (shots 1-3) nor close to it (shots 4-6) and shows that with developed NF-LA-ICP-MS procedure 


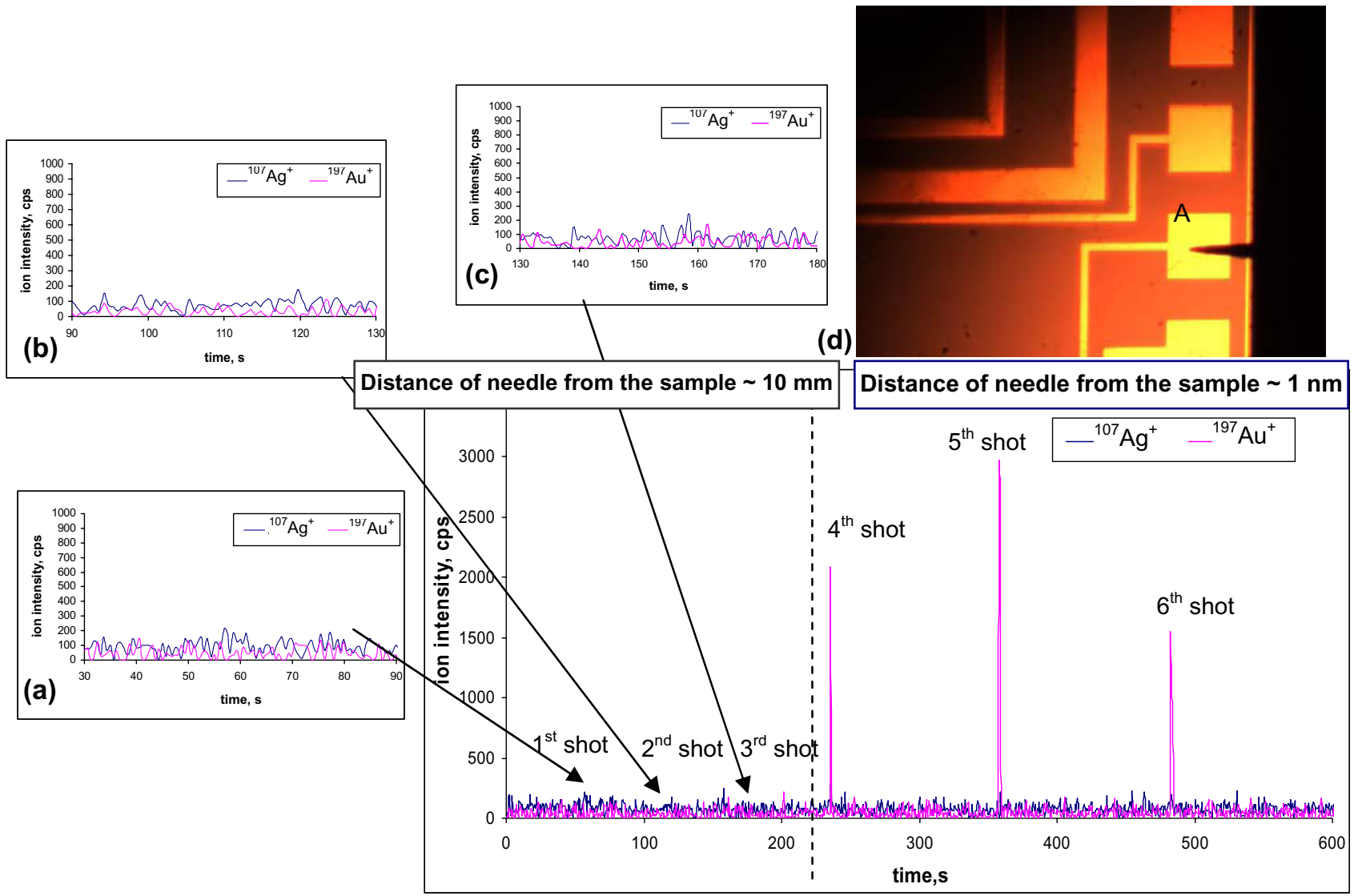

Figure 4. Transient signals of ${ }^{197} \mathrm{Au}^{+}$and ${ }^{107} \mathrm{Ag}^{+}$measured by NF-LA-ICP-MS procedure on analyzed IDA-chip bioelectronic device. Insets (a), (b) and (c) show the enlarged graph sections where the ablation without near-field enhancement was performed; inset (d) shows a camera view of region of interest on analyzed IDA-chip. Peaks from fourth, fifth, and sixth laser shots (produced with near-field enhancement) corresponding to the different position on the sample.

the near-field enhancement takes place selectively on the sample surface.

The dependence of mass spectrometric signal of ${ }^{197} \mathrm{Au}^{+}$as a function of "tip-to-sample" distance in performed NF-LA-ICP-MS experiments is presented on Figure 5. Generally, three different distances, 1, 5, and $10 \mathrm{~nm}$ were selected, whereas the places of NF-laser ablation were changed for each of them and the experiments were repeated in the same measurements run. The show that with the smaller "tip-to-sample" distance (in the range 10-1 $\mathrm{nm}$ ) a higher analyte ion intensity is observed (larger ablation volume), which is in good agreement with our previous findings [30, 31]. It should be also mentioned here that sensitivity in NF-LAICP-MS was found to be in about four orders of magnitude lower in comparison to the sensitivity of LA-ICP-MS. Such a difference in detection efficiency could be explained by the local inhomogeneity of sample surface as well as an additional loss of material in the course of transport to the ICP-MS spectrometer, taking in consideration the relatively small spot size and, therefore, small amount of sample ablated.

\section{Conclusions}

In this study, an analytical procedure for the elemental analysis of nano-bioelectronic devices involved in bioengineering research was developed. Using the established LA-ICP-MS procedure, it was possible to image element distribution on the surface of produced IDAchip. The obtained images of $\mathrm{Au}, \mathrm{Pt}$, and $\mathrm{Ti}$ from structural sample layers of measured microchip as well as $\mathrm{Cr}$, which was considered to be a contamination element, were in a good agreement and corresponded with the layout of the electrode pattern. Furthermore, an experimental setup of established NF-LA-ICP-MS procedure was applied for analysis of IDA bioelectronic device at nanometer resolution scale. The results show of achieved $\sim 100$ times near-field-LA-ICP-MS enhancement of analyte signal, when the needle was positioned in the "near-field region" to the sample surface and the laser shot was performed. In addition, studies of reproducibly for five separated NF-LA shots at different places of the analyzed sample yielded an RSD of the measurement of $16 \%$. The dependence of analyte signal on the "tip-to-sample" distance shows that with smaller distance (in the range 1-10 $\mathrm{nm}$ ) higher analyte ion 
"tip-to-sample" distance: $\mathrm{a}-1 \mathrm{~nm} ; \mathrm{b}-5 \mathrm{~nm} ; \mathrm{c}-10 \mathrm{~nm}$;

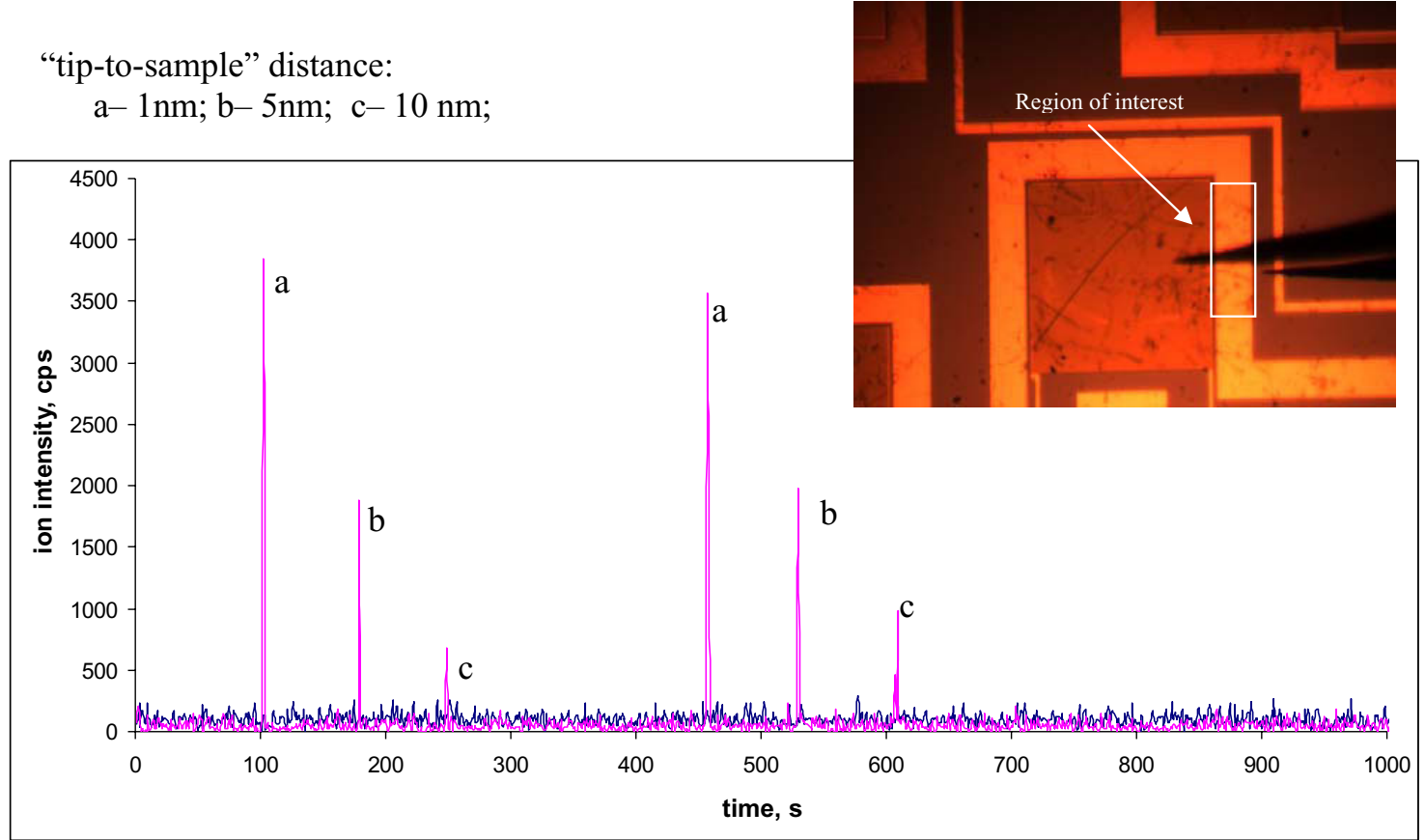

Figure 5. Dependence of analyte ion intensity on "tip-to-sample" distance measured by developed NF-LA-ICP-MS method.

intensity is observed. Based on this study, a further development and improvement of the proposed NFLA-ICP-MS procedure for analyzing (imaging) highly integrated bioelectronic devices in micro- and nanometer resolution will be important in bioengineering.

\section{Acknowledgments}

The authors gratefully acknowledge support of this research by the Deutsche Forschungsgemeinschaft (DFG project (ZO256/1-1). Furthermore, the authors acknowledge the support of Chi Wai Lo during the fabrication of the IDA chips.

\section{References}

1. Becker, J. S. Inorganic Mass Spectrometry: Principles and Application; J. Wiley and Sons: Chichester, 2007; p. 514

2. Bronzino, J. Handbook of Biomedical Engineering; CRC Press LLC: Boca Raton, FL, 2000; p. 3024.

3. Uslu, F.; Ingebrandt, S.; Mayer, D.; Bocker-Meffert, S.; Odenthal, M.; Offenhausser, A. Label-free fully electronic nucleic acid detection system based on a field-effect transistor device. Biosens. Bioelectr. 2004, 19, $1723-1731$.

4. Ivanou, D. K.; Streltsov, E. A.; Fedotov, A. K.; Mazanik, A. V. Electrochemical deposition of nanocrystalline PbSe layers onto p-Si (100) wafers. Th. Sol. Films 2005, 487, 49-53.

5. Gutwirth, J.; Wagner, T.; Nemec, P.; Kasap, S. O.; Frumar, M. Thermal and optical properties of AgSbS2 thin films prepared by pulsed laser deposition (PLD). J. Non-Cryst. Sol. 2008, 354, 497-502.

6. Chiba, D.; Yu, K. M.; Walukiewicz, W.; Nishitani, Y.; Matsukura, F.; Ohno, H. Properties of Ga1-xMnxAs with high x (>0.1). J. Appl. Phys. 2008, 103, 07D136-07D136-3.

7. Mesjasz-Przybylowicz, J.; Przybylowicz, W. J. PIXE on Biological samples. Nucl. Instrum. Method Phys. Res. B 2002, 189, 470.

8. Triyoso, D. H.; Gilmer, D. C.; Jiang, J.; Droopad, R. Characteristics of thin lanthanum lutetium oxide high-k dielectrics. Microel. Eng. 2008, 85, $1732-1735$.

9. Kataoka, Y.; Itani, T. Ultra-shallow depth profiling using SIMS and ion scattering spectroscopy. Surf. Interface Anal. 2007, 39, 826-831.

10. Touboul, D.; Halgand, F.; Brunelle, A.; Kersting, R.; Tallarek, E.; Hagenhoff, B.; Laprevote, O. SIMS. Anal. Chem. 2004, 76, 1550.

11. Pisonero, J.; Fliegel, D.; Gunther, D. High efficiency aerosol dispersion cell for laser ablation-ICP-MS. J. Anal. At. Spectrom. 2006, 21, 922-931.
000
12. Zoriy, M. V.; Becker, J. S. Imaging of elements in thin cross sections of human brain samples by LA-ICP-MS: A study on reproducibility. Int. J. Mass Spectrom. 2007, 264, 175-180.

13. Zoriy, M. V.; Dehnhardt, M.; Reifenberger, G.; Zilles, K.; Beck, J. S. Imaging of $\mathrm{Cu}, \mathrm{Zn}, \mathrm{Pb}$, and $\mathrm{U}$ in human brain tumor resections by laser ablation inductively coupled plasma mass spectrometry. Int. J. Mass Spectrom. 2006, 257, 27-33.

14. Zoriy, M. V.; Matusch, A.; Spruss, T.; Becker, J. S. Laser ablation inductively coupled plasma mass spectrometry for imaging of copper zinc, and platinum in thin sections of a kidney from a mouse treated with cis-platin. Int. J. Mass Spectrom. 2007, 260, 102-106.

15. Tang, J. H.; Gu, L. X.; Zhang, Z. Z.; Wu, C. Z.; San, J. Z.; Wang, C. S.; Liu, S. H.; Zhang, G. H. Characteristics, age, and origin of the Xianshuiquan gneissose granite in eastern Tianshan. Acta Petrolog. Sin. 2007, 23, $1803-1820$.

16. Wang, X. L.; Zhou, J. C.; Griffin, W. L.; Wang, R. C.; Qiu, H. S.; O'Reilly, S. Y.; Xu, X. S.; Liu, X. M.; Zhang, G. L. Detrital zircon geochronology of Precambrian basement sequences in the Jiangnan orogen: Dating the assembly of the Yangtze and Cathaysia Blocks. Precambr. Res. 2007, 159, 117-131.

17. Gregory, C. J.; Rubatto, D.; Allen, C. M.; Williams, I. S.; Hermann, J.; Ireland, T. Allanite micro-geochronology: A LA-ICP-MS and SHRIMP U-Th-Pb study. Chem. Geol. 2007, 245, 162-182.

18. Guillong, M.; Heimgartner, P.; Kopajtic, Z.; Gunther, D.; GuntherLeopold, I. A laser ablation system for the analysis of radioactive samples using inductively coupled plasma mass spectrometry. J. Anal. At. Spectrom. 2007, 22, 399-402.

19. Sarah, G.; Gratuze, B.; Barrandon, J. N. Application of laser ablation inductively coupled plasma mass spectrometry (LA-ICP-MS) for the investigation of ancient silver coins. J. Anal. At. Spectrom. 2007, 22, 1163-1167.

20. Resano, M.; Ruiz, E. G; Mihucz, V. G.; Moricz, A. M.; Zaray, G. Vanhaecke, F. Rapid screening method for arsenic speciation by combining thin layer chromatography and laser ablation-inductively coupled plasma-dynamic reaction cell-mass spectrometry. J. Anal. At. Spectrom. 2007, 22, 1158-1162.

21. Fernandez, B.; Claverie, F.; Pecheyran, C.; Donard, O. F. X. Direct analysis of solid samples by FS-LA-ICP-MS. TrAC 2007, 26, 951-966.

22. Becker, J. S.; Matusch, A.; Depboylu, C.; Dobrowolska, J.; Zoriy, M. V. Quantitative imaging of selenium, copper, and zinc in thin sections of biological tissues (Slugs-genus arion) measured by laser ablation inductively coupled of plasma mass spectrometry. Anal. Chem. 2007, 79, 6074-6080.

23. Venkatachalam, A.; Koehler, C. U.; Feldmann, I.; Lampen, P.; Manz, A. Roos, P. H.; Jakubowski, N. Detection of phosphorylated proteins blotted onto membranes using laser ablation inductively coupled plasma mass spectrometry. J. Anal. At. Spectrom. 2007, 22, 1023-1032.

24. Becker, J. S.; Zoriy, M.; Dobrowolska, J.; Matusch, A. Laser ablation inductively coupled plasma mass spectrometry (LA-ICP-MS) in elemen- 
tal imaging of biological tissues and in proteomics. J. Anal. At. Spectrom. 2007, 22, 736-744.

25. Sekaran, N. Laser ablation-inductively coupled plasma mass spectrometry for 2D mapping of trace elements in soft tissue. Curr. Sci. 2006, 90, 221-225.

26. Becker, J. S.; Zoriy, M.; Wu, B.; Matusch, A. Imaging of essential and toxic elements in biological tissues by LA-ICP-MS. J. Anal. At. Spectrom. 2008, 23, 1275-1280.

27. Zoriy, M. V.; Dehnhardt, M.; Matusch, A.; Becker, J. S. Comparative imaging of $\mathrm{P}, \mathrm{S}, \mathrm{Fe}, \mathrm{Cu}, \mathrm{Zn}$, and $\mathrm{C}$ in thin sections of rat brain tumor as well as control tissues by laser ablation inductively coupled plasma mass spectrometry. Spectrochim. Acta. B 2008, 63, 375-382.

28. Zoriy, M. V.; Kayser, M.; Izmer, A. V.; Pickhardt, C.; Becker, J. S. Determination of uranium isotopic ratios in biological samples using laser ablation inductively coupled plasma double focusing sector field mass spectrometry with cooled ablation chamber. Int. J. Mass Spectrom. 2005, 242, 297-302.

29. Koch, J.; Gunther, D. Femtosecond laser ablation inductively coupled plasma mass spectrometry: achievements and remaining problems. Anal. Bioanal. Chem. 2007, 387, 149-153.

30. Zoriy, M. V.; Kayser, M.; Becker, J. S. Possibility of nano-local element analysis by near-field laser ablation inductively coupled plasma mass spectrometry (LA-ICP-MS): New experimental arrangement and first application. Int. J. Mass Spectrom. 2008, 273, 151-155.
31. Zoriy, M. V.; Becker, J. S. Near-field laser ablation inductively coupled plasma mass spectrometry (LA-ICP-MS): A novel elemental and isotopic analytical technique at nanometer scale. Rapid Commun. Mass Spectrom. 2009, 23, 23-30.

32. Becker, J. S.; Zoriy, M. V.; Pickhardt, C.; Palomero-Gallagher, N.; Zilles, K. Imaging of Copper, Zinc, and Other Elements in Thin Section of Human Brain Samples (Hippocampus) by Laser Ablation ICP-MS. Anal. Chem. 2005, 77, 3208-3216.

33. Becker, J. S.; Zoriy, M. V.; Dehnhardt, M.; Pickhardt, C.; Zilles, K. Copper, zinc, phosphorus, and sulfur distribution in thin section of rat brain tissues measured by laser ablation inductively coupled plasma mass spectrometry: Possibility for small-size tumor analysis. J. Anal. At. Spectrom. 2005, 20, 91

34. Zoriy, M. V.; Kayser, M.; Izmer, A. V.; Pickhardt, C.; Becker, J. S. Determination of uranium isotopic ratios in biological samples using laser ablation inductively coupled plasma double focusing sector field mass spectrometry with cooled ablation chamber. Int. J. Mass Spectrom. 2005, 242, 297-302

35. Pickhardt, C.; Dietze, H. J.; Becker, J. S. Laser ablation inductively coupled plasma mass spectrometry for direct isotope ratio measurements on solid samples. Int. J. Mass Spectrom. 2005, 242, 273-280.

36. Izmer, A. V.: Zoriy, M. V.; Pickhardt, C.: Quadakkers, W.; Shemet, V. Singheiser, L.; Becker, J. S. LA-ICP-MS studies of cross section of NiCrAlY-based coatings on high-temperature alloys. J. Anal. At. Spectrom. 2005, 20, 918-923. 